Boletim Científico do Instituto Agronômico do Estado de S. Paulo

Vol. 26

Campinas, agôsto de 1967

N. ${ }^{\circ} 24$

\title{
COMPORTAMENTO DE VARIEDADES DE ALFACE NA REGIÃO DE CAMPINAS $(1,2)$
}

José BotTer Bernard, engenheiro-agrônomo, Seção de Olericultura, e Toshio IGUE, engenheiro-agrônomo, Seção de Técnica Experimental, Instituto Agronômico

\section{SINOPSE}

São apresentados os resultados de ensaio de variedades de alface pertencentes a diferentes tipos.

Além da produtividade e qualidade do produto, o trabalho visou verificar o comportamento das variedades nas condiçốes de temperaturas elevadas reinantes em agôsto-outubro, fim do periodo cultural recomendável nas condições do planalto paulista.

A variedade "Great Lakes" superou enormemente as demais em produtividade e tipo das cabeças. A "Maravilla de las Cuatro Estaciones", a segunda colocada, revelou grande tolerância ao calor.

\section{I - INTRODUC̣ÃO}

A alface (Lactuca sativa L.) é uma hortaliça de inverno que produz bem, nas condições do Estado de São Paulo, na época mais fresca do ano (1). A temperatura média mensal mais indicada para o bom desenvolvimento das plantas e para uma boa produção, varia de 15,5 a $18,3^{\circ} \mathrm{C}(\boldsymbol{2})$.

No presente trabalho são apresentados os reșultados de um ensaio, instalado na Estaçāo Experimental "Theodureto de Camargo", do Instituto Agronômico, em Campinas, no qual entraram em competição oito variedades dessa hortaliça.

(1) Trabalho apresentado na VI Reuniáo Anual da Sociedade de Olericultura do Brasil, realizada em Campinas, S.P., de 17 a 23 de julho de 1966 . Recebido para publicaçáo em 12 de maio de 1967.

(2) A FAPESP colaborou na obtenção dos dados experimentais. 
O experimento teve como principal objetivo, verificar quais as melhores variedades, sob os aspectos de produtividade e qualidade do produto. Visou também determinar o comportamento das variedades face às temperaturas reinantes no período de fim de inverno a principio de primavera, portanto no limite recomendável para o local do ensaio.

\section{2 - MATERIAL E MÉTODOS}

As oito variedades estudadas, pertencentes a diferentes tipos de alface, são de diversas procedências, porém as sementes utilizadas neste ensaio foram produzidas nas estações experimentais do Instituto Agronômico, em Campinas e Monte Alegre do Sul.

Quatro dentre elas são de cabeça com fôlhas lisas, do tipo que os norte-americanos denominam "Butter-head", e que conta com as preferências do consumidor brasileiro: "White Boston I-2896", “Shimabukuro I-2673", “Gigante I-1797”, e "Piracicaba I-2575". A White Boston, recebida em 1960 dos Estados Unidos, foi a mais delicada e de melhor qualidade. A Shimabukuro, recebida em 1957, é menos delicada que a anterior, e produz cabeças menos compactas. A Gigante foi recebida em 1950, e a Piracicaba veio de Ribeirão Prêto, em 1956, e foi obtida de sementes cedidas pela Escola Superior de Agricultura "Luiz de Queiroz", Piracicaba; estas duas últimas variedades, bastante semelhantes, não "fecham" bem; produzem um tufo de fôlhas grandes, verdes e mais ou menos onduladas.

A "Maravilla de las Cuatro Estaciones I-2866", procedente da Uniāo Soviética e recebida em 1959, é do mesmo tipo das anteriores; produz cabeças bem compactas, porém as fôlhas externas, um tanto consistentes, apresentam uma tonalidade roxo-avermelhada.

A “Great Lakes - 118 I-2912", recebida em 1960, é do tipo de cabeça com fôlhas crespas, que os norte-americanos preferem e denominam "Crisp-head".

A “B. S. Simpson I-2391", introduzida em 1954, proveniente dos Estados Unidos, pertence ao tipo "de fôlha", caracteriza-se por suas fôlhas crespas, verde-amareladas, e não produz cabeças.

Esta variedade que, entre nós, é conhecida por "Fôlha de Seda”, possui a particularidade de produzir sementes de coloração escura, daí a razão do seu nome (Black-Seeded-Simpson). 
Finalmente, a "Romana Branca I-2038", do tipo romano, com cabeças fôfas, alongadas, e fôlhas lisas, consistentes, compridas, ovaladas, de côr verde-clara, foi adquirida em 1953, em São Paulo.

O experimento foi conduzido em solo areno-argiloso de formação glacial e de acidez média. A análise química do solo, efetuada pela Seção de Fertilidade do Solo, do Instituto Agronômico, revelou os seguintes resultados: $\mathrm{pH}, \mathbf{5 , 4 0}$; carbono, $1,08 \%$; fósforo, 0,37 ; potássio, 0,37 ; cálcio e magnésio, 3,50; alumínio, traços. Os teores de fósforo, potássio, cálcio, magnésio e alumínio, em e.mg por $100 \mathrm{ml}$ de T. F. S. A.

A adubação empregada por metro quadrado de terreno foi de $10 \mathrm{~kg}$ de composto, $250 \mathrm{~g}$ de superfosfato simples, $15 \mathrm{~g}$ de cloreto de potássio e $80 \mathrm{~g}$ de Nitrocálcio. Os três primeiros fertilizantes foram incorporados ao solo 7 dias antes do transplante das mudas, e o adubo nitrogenado aplicado em cobertura, em quatro parcelas iguais, aos 15, 2025 e 30 dias após aquela operação.

A semeadura teve lugar no dia 5 de agôsto, o transplante em $1 .^{\circ}$ de setembro, e as colheitas na segunda quinzena de outu. bro de 1965. Nesse período as temperaturas médias mensais do ar foram de $19,2^{\circ} \mathrm{C}, 22,6^{\circ} \mathrm{C}$ e $21,2^{\circ} \mathrm{C}$, para os meses de agôsto, setembro e outubro, respectivamente $\left(\begin{array}{lll}4 & \text { e } & 5\end{array}\right)$. A temperatura mínima registrada foi de $0,6^{\circ} \mathrm{C}$, em agôsto, e a máxima, de $35,4^{\circ} \mathrm{C}$, em setembro. A média das mínimas, para o trimestre, foi de $15,0^{\circ} \mathrm{C}$, e a das máximas, de $28,1^{\circ} \mathrm{C}$.

Empregou-se o delineamento de blocos ao acaso, repetidos 5 vêzes, em canteiros de $2,52 \mathrm{~m}^{2}(1,20 \times 2,10 \mathrm{~m})$. O espaçamento adotado foi de $30 \times 30 \mathrm{~cm}$, de modo que cada canteiro constou de 4 linhas com 7 plantas cada, no total de 28 plantas por canteiro.

\section{3 - RESULTADOS E DISCUSSÃO}

No quadro 1 são apresentados os resultados das produçōes obtidas por metro quadrado, assim como o pêso médio de uma planta de cada variedade separadamente.

Os resultados da análise estatística das produções totais em pêso, considerando as plantas comerciáveis, mostraram o seguinte: dades.

1 - Houve diferença altamente significativa entre as varie- 
Quadro 1. - Produção e pêso médio de plantas comerciáveis de alface, obtidos em ensaio de variedades conduzido em Campinas

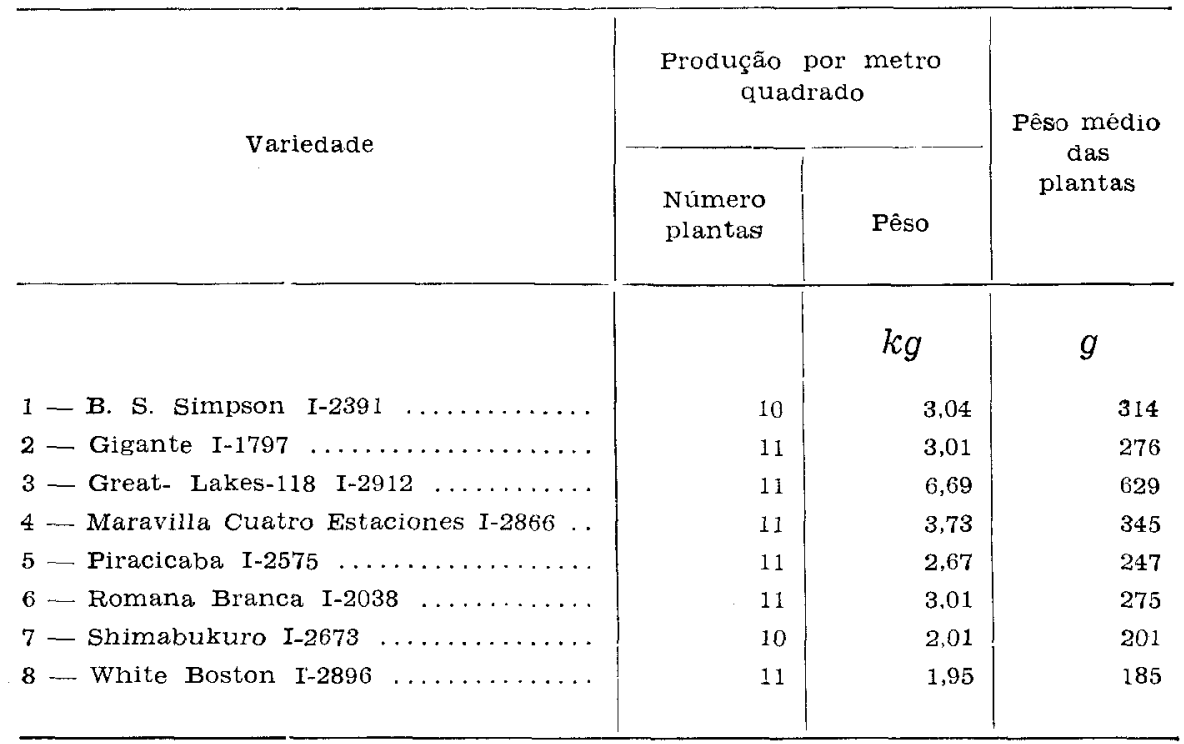

2 - Aplicando-se o teste de Tukey, ao nível de 5\%, na comparação das médias das variedades, verificou-se que a "Great Lakes-118" foi superior às demais. Desta variedade, a planta maior alcançou 1.420 gramas.

3 - A "Maravilla de las Cuatro Estaciones" foi inferior a Great Lakes, mas superou as restantes.

4 - Entre as variedades B. S. Simpson, Romana Branca, Gigante e Piracicaba, não houve diferenças significativas. Estas duas últimas variedades não produziram cabeças bem fechadas.

5 - Finalmente, a variedade menos produtiva foi a White Boston, que não diferiu da Shimabukuro. Apresentou-se com melhor aparência, e a planta maior pesou 490 gramas.

\section{4 - CONCLUSÕES}

Nas condições do presente ensaio, evidenciou-se que a alface variedade Great Lakes-118 I-2912, do tipo "Crisp-head", superou tôdas as demais, em produção, tamanho das plantas e formação 
cle cabeças, confirmando os resultados obtidos pelos experimentadores norte-americanos. Esta alface produziu bem, mesmo fora dos limites de temperatura considerados ótimos para a cultura (3).

A "Maravilla de las Cuatro Estaciones, I-2866", que se colocou em segundo lugar em produção, também revelou tolerância ao calor, fato comprovado pela formaçāo de boas, cabeças. Contudo a pigmentação deprecia o valor comercial.

As variedades dos tipos "de fôlha" e "romano" foram superadas pelas anteriores em produção e qualidade, porém as menos produtivas foram as do tipo "Butter-head", principalmente a "White Boston", que de tôdas é a mais delicada.

\section{BEHAVIOR OF LETTUCE VARIETIES IN THE CAMPINAS AREA}

\section{SUMMARY}

Results are presented hereunder concerning a trial installed in Campinas, in which no less than 8 varieties of lettuce (Lactuca sativa L.), belonging to different types, were tried.

The main purpose of the trial was to verify which were the best varieties considering productivity and quality. An attempt was made to determine equally the behavior of the varieties in regard to temperatures existing in the period, in plantings carried out in August-October, this being the limit recommended for the conditions of the S. Paulo plateau.

In this period the mean monthly temperatures of the air were $19.2^{\circ} \mathrm{C}$, $22.6^{\circ} \mathrm{C}$ and $21.2^{\circ} \mathrm{C}$, for the months of August, September and October, respectively.

- From the results obtained it can be seen that variety Great Lakes-118 I-2912, belonging to the Crisp-head type, outdid all of the others in yield, size of plants and formation of heads. The Maravilla de Las Cuatro Estaciones I-2866 ranked second in yield, revealing that it stood warm weather fairly well, as it proved with the formation of good heads. This variety belongs to the Butter-head type, however with the external leaves consistent and of brownish tint.

The varieties of Leaf and of the Cos or Romaine types, as B. S. Simpson I-2391 and Romana Branca I-2038, were excelled by the foregoing in yield and quality. The same was observed with the Gigante I-1797 and Piracicaba I-2575 varieties, which belong to the Butter-head type.

The least productive ones were White Boston I-2896 and Shimabukuro I-2673, also belonging to the Butter-head type. The White Boston is the tenderest and most delicate of them all and of the most commercial demand of the $\mathbf{S}$. Paulo market as well. 


\section{LITERATURA CITADA}

1. BERNARDI, JOSÉ BOTTER. Instruções para a cultura da alface. Campinas, Instituto Agronômico, 1956. 8p. (Boletim 76)

2. KNOTT, JAMES EDWARD. Handbook for vegetable growers. New York, John Wiley \& Sons, 1957. 238p.

3. - - Palestras sôbre horticultura proferidas na Escola Superior de Agricultura "Luiz de Queiroz". São Paulo, Universidade, 1951 . p.1-32.

4. Resumo dos dados meteorológicos de Campinas - Agôsto e Setembro de 1965. Agronômico, 17(9/10):55-60, 1965.

5. Resumo dos dados meteorológicos de Campinas - Outubro de 1965. Agronômico, 17(11/12):35-40, 1965. 